\title{
Layering Learning for Work-Readiness in a Science Programme
}

\author{
McKay, Marianne. ${ }^{a}$; Smith-Tolken, Antoniette ${ }^{\mathrm{b}}$ and Alessandri, Anne
}

${ }^{a}$ Department of Viticulture and Oenology, Stellenbosch University, South Africa,.

${ }^{\mathrm{b}}$ Divisionfor Social Impact, Stellenbosch University, South Africa.

${ }^{c}$ Institute for Grape and Wine Sciences, Stellenbosch University, South Africa

\begin{abstract}
In order to prepare our students for a challenging workplace, the Department of Viticulture and Oenology at Stellenbosch University in South Africa have implemented Engaged Teaching and Learning (ETL) strategies in the four-year undergraduate degree. In this project, we assessed the effects of service-learning (SL) and a six-month internship on graduate employability by analysing student reflections that had been collected over a number of years. We also asked industry members whether they felt students had improved in key areas after the final year internship. The student submissions for SL showed evidence of personal growth and transformation, and those for the internship reflected industry requirements for practical and other skills in a complex and technically demanding environment. It was found that these innovative and engaged experiences gave students opportunities for self-questioning and personal growth, which is unusual in the 'hard' sciences. Overall, the layered approach (ETL in successive years of the programme) was found to enhance professional attributes advocated by industry professionals, and provide sound preparation for working life. To our knowledge, this alignment of community/industry, academic institution and student in monitoring learning and graduate attributes is a novel approach in science.
\end{abstract}

Keywords: Engaged Teaching \& Learning; work-readiness; graduate attributes, science. 


\section{Introduction}

Graduates moving into employment in the agricultural sector in the current South African (SA) context are facing, arguably, some of the most fraught working conditions in the world. A stagnant economy, rampant unemployment, climate change and a history that includes exploitation, racism and deep injustices which still permeate the work context. In addition, Higher Education institutions in SA, and Stellenbosch University (SU) in particular, face complex issues, including calls to decolonise institutions and curricula. With corruption and deep imbalances in SA society seeming to intensify daily, the need to instill ethical, critical citizenship, sensitivity and the ability to cope with the complexity 'out there' in our graduates is increasingly important, but challenging within the context of conservative scientific curricula. Fink (2015) notes that a service experience involving significant community issues can be a powerful learning experience will engage students in their own learning will change their lives. An 'engaged institution' will be organized to respond to the needs of current and future students (CIC, 2005), through partnering university knowledge and resources with those of the public and private sectors. This strategy will prepare engaged citizens, strengthen democratic values and civic responsibility, address critical societal issues, and contribute to the public good. McNall et al (2009) noted that as HE has engaged with communities, a new form of scholarship engaged scholarship - has emerged that cuts across teaching, research, and service.

In order to prepare our students for challenges in the workplace, the Department of Viticulture and Oenology at SU in the Western Cape implemented innovative engaged teaching and learning (ETL) strategies in the four-year undergraduate degree which align community/industry, academic institution and student in monitoring learning and graduate attributes. In this project, we assess the effects of these strategies (with a specific focus on the Internship aspects), and whether they help to 'future-proof' our students for a the workplace. In order to do this, we also needed to establish what professional attributes were prioritized by our industry, and measure whether these had been affected by our 'layered learning' approach.

\section{ETL Strategies in Viticulture and Oenology}

\subsection{Service-learning (SL)}

Many universities across the world prefer service-learning as pedagogical framework and practice to integrate community engagement in teaching and learning, but it is less common in the natural sciences. It is a teaching approach that enhances students' understanding of theoretical content through thoughtfully organized service and real life experience (Lazarus, 2007), where service to the community and learning goals are of 
equal weight and benefit (Furco, 2003). Importantly, SL fosters reciprocal relationships with community partners (Lazarus, 2007) while enhancing the academic curriculum through active reflection on learning (Bender, 2006). The focus of service-learning on personal growth, academic learning and social responsibility articulates well with the aims of HE to develop student graduate attributes such as professionalism, critical citizenship and employment competencies..

\subsection{Internships}

Internships usually require longer regular exposure to workplace learning. In one of the few peer-reviewed studies available on internships in science, Scholz, et al, (2004) investigated the benefits of a compulsory internship in environmental science education. In their study, the authors identified key 'qualifications' which transcended the boundaries of a specific discipline, ie: communication skills, organization of work, and provision of information. They suggested that an internship is a good tool to promote these and other skills and abilities and that it should be a compulsory part of the curriculum (Scholz, et al, 2004). King \&Schweitzer (2014) argue that internships are more than work-placements, and are a high-impact educational practice, with important consequences for learning as long as the criteria outlined by Kuh (2008) are met. These are: that students invest time and effort, interact with faculty and peers about substantive matters, experience diversity, reflect and integrate learning; and learn through real-world applications.

\subsection{Implementation of ETL within the SU Viticulture and Oenology Programme}

Engaged strategies are layered throughout the programme, culminating in an extended internship (6 months in industry) in the final (fourth year). These strategies include investigations into social issues in Western Cape, Health \& Safety Audits in commercial wineries, and service-learning (SL) at the beginning of the second year. There are normally 30 - 35 students per academic year on the programme. Students are placed in tasting rooms in second year for SL for around a month (a minimum of 25 hours). They will work intermittently during this time, but frequently end up in long term employment at the farm. The internship period is from the end of third year to the middle of fourth year, during which time students do not return to campus, but work continuously at the estate/wine farm carrying out viticultural and cellar duties while experiencing the entire harvest process, from grape ripeness monitoring to the finished wine in bottles. They often live on the farms, and earn a cellar-hand's wage, and will interact intensively with staff.

McNall, et al (2009) stated that an important component of the students' (as well as staff members) activities is to reflect on their experiences. In our programme, this takes the 
form of three reflections on the SL work (before, during and after) in which students analyse intersections (or lack thereof) between their academic work, and their 'real-life' experience of wines and consumers. After the internship in fourth year, students submit two reports: a research report based on a small piece of scientific research at the farm, written in the scientific style (third person past perfect), and a routine work report, written in the first person. This contains reflections on daily activities and experiences. Students are mentored by winemakers and viticulturalists on the farm, and by academics at the Department during this time. They are also supported by a full-time internship liaison officer.

\section{Project Methodology}

In order to analyse how effective our ETL had been in improving student learning, graduate attributes and professional attributes, we analysed three sets of data.

a) Second year student SL reflections were ( $\sim 0$ reports collected over three years)

b) Fourth year internship routine work reports, ( 80 reports over four years)

c) Industry members: online questionnaire (one occurrence)

Data was collected on the SU on-line learning platform "SunLearn", and texts were aggregated and coded using qualitative data analysis software AtlasTI TM. Data was coded using strategies as outlined by Saldana (2016). The initial coding cycle in which identified broad themes (Table 1), was followed by second and third coding cycles which extracted subthemes around participants personal and identity development. Ethical clearance for the study was obtained (SU-HSD-002378).

\section{Results}

\subsection{Service-learning}

Student submissions for the SL yielded 22 different codes (Table 1) in four broad themes (academic knowledge, work-experience related and personal /perceptions). As was expected in a personal reflection, most content related to their own personal growth. They reflected in depth on their academic content, and the areas in which they had experience which made them feel better prepared for the world of work. The two codes that were highest in frequency were "consumer/marketing interaction" $(\mathrm{n}=100)$ and "positive experience" $(\mathrm{n}=96)$. 
Table 1. Frequency of codes generated for themes in Service Learning submissions.

\begin{tabular}{llc}
\hline Code area & Code & $\begin{array}{c}\text { Frequenc } \\
\text { y (n) }\end{array}$ \\
\hline ACADEMIC & $\begin{array}{l}\text { wine/product knowledge, consumer/marketing } \\
\text { interaction knowledge embedded }\end{array}$ & 243 \\
WORK- & $\begin{array}{l}\text { work experience, new knowledge, people skills, } \\
\text { communitywine industry, critical thinking/big picture, }\end{array}$ & 315 \\
RELATED & $\begin{array}{l}\text { leadership/responsibility, work-readiness } \\
\text { Pratitude, life goal, negative experience, personal growth } \\
\text { PERSONAL/ }\end{array}$ & 376 \\
PERCEPTIONS & $\begin{array}{l}\text { altered perspective, discomfort and insecurity, } \\
\text { confidence }\end{array}$ & \\
Coded items & & 934 \\
\hline
\end{tabular}

A breakdown of student perception codes can be seen in Figure 1 which shows that there were also negative (uncomfortable) emotions associated with the work experience, and some insecurity (especially at the start of the service-learning period).

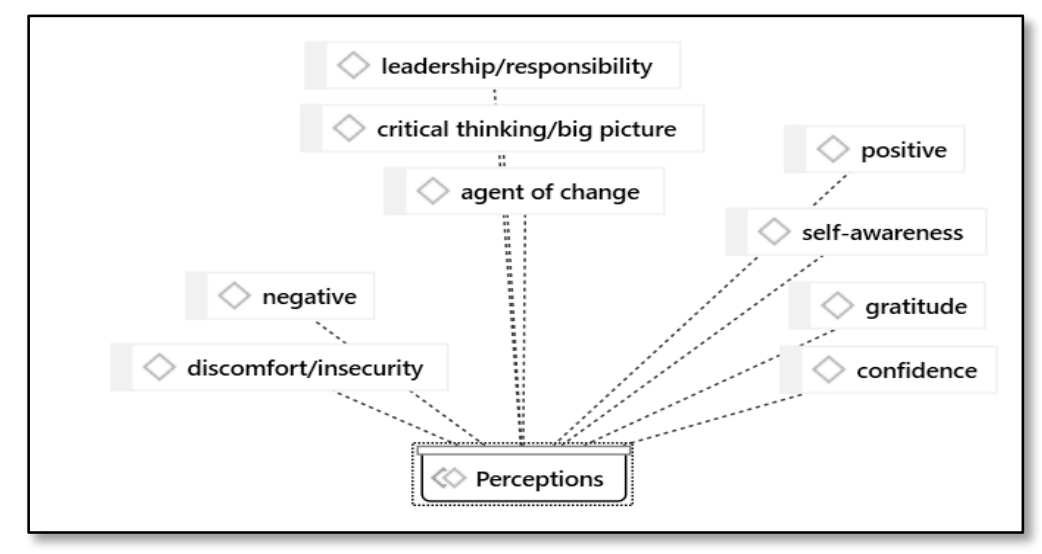

Figure 1. Detailed codes for sub-theme "perceptions" after Service-Learning..

Figure 2 gives some direct quotations from the student reflections, in which it is clear that even though this was a short period in their academic career, it was transformative in nature, leading them to reflect on their career path, industry and even their own personalities. 


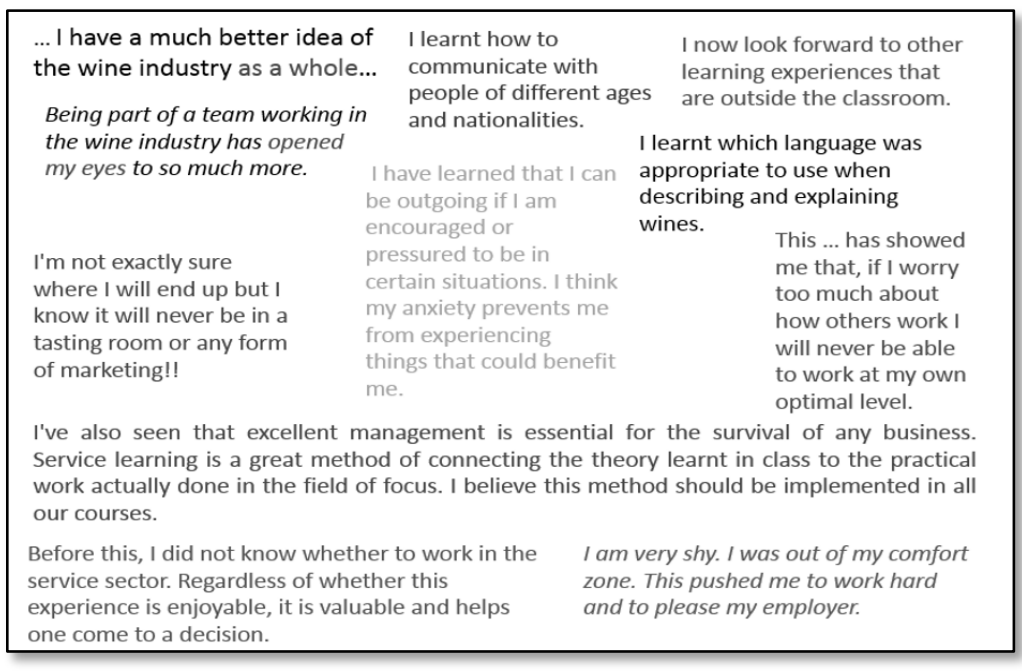

Figure 2. Selected comments from reflections after Service-Learning.

\subsection{Internship}

The Internship period in the final year takes the work-readiness of the student to the next level. This is evident from their routine work submissions $(n=\sim 80)$ in which they reflect on their daily tasks and learning over the six-month period. The total immersion in the work environment is again uncomfortable for them, (particularly at the start of the harvest) and students describe feeling out of their depth, embarrassed, anxious, annoyed or worried by their lack of experience, as they did for their SL. However, by the end of the harvest, levels of confidence are high and accompanied by critical thinking linking a number of aspects of their work experience (Figure 3), and their personal feelings concerning the wine industry in South Africa, and their place in it.

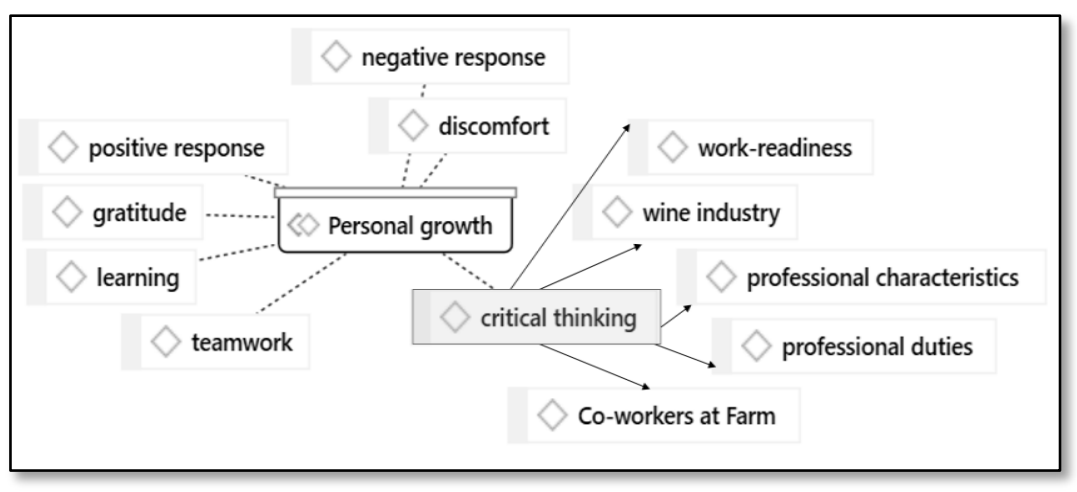

Figure 3. Codes associated with "critical thinking” sub-themeafter Internship period in fourth year. 
Professional characteristics such as punctuality, being organized and diligent, taking initiative, being proactive and reliable are now discussed by students as important in the working environment, and coincide with those attributes cited by industry as being valuable (Table 2). Awareness of the complexities and social issues within the industry were also highlighted as problems to be solved going forward.

Table 2. Characteristics identified by wine industry members $(n=21)$ impacted by the Internship.

\begin{tabular}{lcc}
\hline Professional attribute & $\begin{array}{c}\text { Chosen by industry members } \\
\text { as essential attribute }\end{array}$ & $\begin{array}{c}\text { Improvement after } \\
\text { internship? }\end{array}$ \\
\hline reliability & 18 & 12 \\
teamwork & 16 & 14 \\
proactive attitude & 14 & 12 \\
problem solving & 13 & 7 \\
organizational skills & 12 & 9 \\
technical skills (vineyard, winery, tasting) & 7 & 11 \\
critical thinker & 7 & 9 \\
Positive impact of Internship overall & & $\mathbf{1 9}$ \\
Employability improved & & $\mathbf{1 6}$ \\
\hline
\end{tabular}

Students worked alongside a varied complement of staff (Figure 4) from all areas of South African society, and recognized the intense value of mentorship not only from their 'official' Internship mentors (winemakers and viticultural experts) but also from cellar hands and vineyard workers. Knowledge production worked both ways, with students bringing new scientific findings from the academic environment, and learning key skills from co-workers at the farms, as well as an increased sensitivity for working conditions.

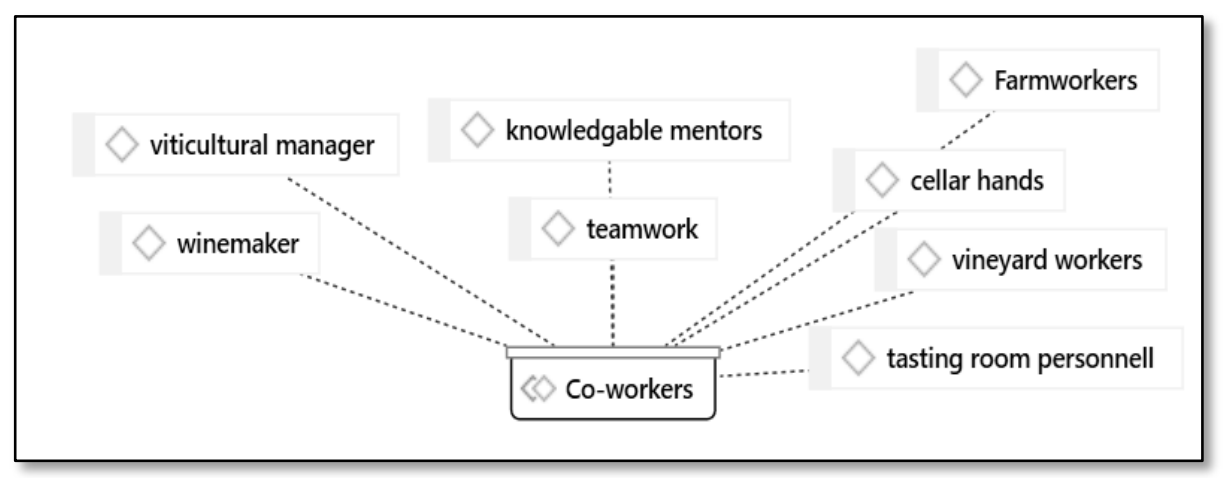

Figure 4. Codes associated with the sub-theme "Co-workers" after the internship. 


\section{Discussion and Conclusions}

Engaged strategies like service-learning and the internship give our students the opportunity to apply academic knowledge in a real-world setting, work and learn alongside a diverse group of people, and reflect on their experiences. We are therefore satisfied that Kuh's (2008) criteria including purposeful tasks, opportunities for reflection, building substantive relationships and engaging across differences, were met in this programme. Engaged experiences are solid preparation for working life, as well as giving students an important (and often humbling) sense of themselves in the broader industry. It was also the case, as asserted by Boler (1996) that the discomfort associated with the workplace provided excellent opportunities for self-questioning and personal growth, which is unusual in the sciences. Our results indicated that ETL enhanced graduate attributes and professional characteristics, with 19 of 21 industry members indicating an overall positive impact, and $76 \%$ of these potential employers agreeing that employability had improved. Skills such as organization of work, reliability, and technical abilities seemed enhanced according to industry feedback. Internships also seemed to promote problem solving and teamwork, both important in a South African context. There are clear shifts in focus within the student reflections concerned with learning, interaction with the community, and their own transformation. There is also an interchange of social commodities, which are developed together in the cyclic process, particularly in the internship engagement, which relies heavily on sustainable, reciprocal relationships with excellent mentors. Knowledge is created through the interactions, and meaning-making occurs individually, concurrently and collaboratively. This suggests that engaged teaching and learning strategies within a Higher Education curriculum are of high value to professional education in science.

\section{References}

Bender, G. Daniels, P. Lazarus, J. Naude, L. Sattar, K., (2006). Service-Learning in the Curriculum, A Resource for HE Institutions HE Quality Committee (HEQC), Council for Higher Education, South Africa. http://www.che.ac.za/media_and_publications/research/service-learning-curriculumresource-higher-education-institutions

Boler, Megan. (1999) Feeling Power: Emotions and Education. New York: Routledge, ISBN-13: 978-0415921046

Committee on Institutional Cooperation (CIC), Committee on Engagement, (2005). Engaged Scholarship: A Resource Guide. http://www.btaa.org/docs/defaultsource/technology/engaged_scholarship.pdf?sfvrsn=481c09b5 2

Fink, L.D (2015) Creating Significant Learning Experiences: An Integrated Approach to Designing College Courses. Jossey-Basse, Wiley. (Publ) ISBN 978-1-118-41632-7

King, M \& Schweitzer, H. (2014) A Pedagogy of Internship. Proceedings of the Symposium on Applied Learning in Higher Education. https://www.academia.edu/6494106/A_Pedagogy_of_Internship 
Kuh, G.D (2008) High-Impact Educational Practices: What They Are, Who Has Access to Them, and Why They Matter (eBook Versioniation of American Colleges and Universities: LEAP, Making Excellence Inclusive. ISBN978-0-9796181-4-7

Furco, A. (2003). Issues of Definition and Program Diversity in the Study of ServiceLearning. In Billig, S.H. and Waterman, A.S. (eds.). Studying Service-Learning: Innovations in Education Research Methodology. New Jersey: Lawrence Erlbaum Associates

Lazurus, J. (2007). Embedding Service Learning in South African Higher Education: The Catalytic Role of the CHESP Initiative Education as Change, Volume 11 Number 3, Dec 2007, Special Issue: CSL pp91-108

McNall, M. Sturdevant, C. Reed, R., Brown, A. (2009) Brokering Community-University Engagement, Innovative Higher Education, , Volume 33, Issue 5, pp 317-331

Saldana, J.(2016) The Coding Manual for Qualitative Researchers. Sage Publications ISBN 978-1-4739-0248-0

Scholz, R., Steiner,R., Hansmann, R. (2004) Role of Internship in Higher Education in Environmental Sciences. J. Res. Sci. Teaching Vol. 41, No. 1, PP. 24-46 